\title{
LA CONSTITUCIÓN POLÍTICA ROMANA EN LA CRISIS REPUBLICANA
}

\author{
Alejandro San Francisco Reyes \\ Profesor de Historia del Derecho y de Historia de Roma \\ Pontificia Universidad Católica de Chile
}

\section{INTRODUCCION}

Siempre resulta interesante revisar los conceptos políticos de los romanos. En efecto, si bien habitualmente consideramos que el legado fundamental de Roma hacia Occidente es el derecho romano ${ }^{1}$, estimamos en general que esto se refiere al ámbito privado, marcado por la tradición recogida a través del Derecho Común europeo ${ }^{2}$ y luego por su proyección en Hispanoamérica ${ }^{3}$. Lo mismo ocurre tiempo después con la recepción del elementos del derecho romano en la codificación civil chilena ${ }^{4}$ y con la anterior incorporación de su estudio en la enseñanza jurídica en Chile, desde la Universidad de San Felipe a partir de 1756 y durante el siglo XIX a partir de la fundación de la Universidad de Chile (1942) y la Universidad Católica (1888) ${ }^{5}$.

Sin embargo, en el ámbito público o político, incluso en el histórico, Roma tiene menor importancia y la mayoría de las veces no se considera su valor en la formación de instituciones o en la definición de conceptos de gobierno importantes. Esto no sólo es curioso, sino claramente erróneo, ya que la presencia de instituciones romanas en la historia, con las lógicas transformaciones de tiempo, lugar y circunstancias, nos pueden llevar a comprender la inmensa tradición que también en el plano constitucional tiene la sociedad romana en la cultura occidental y chilena.

No cabe duda alguna de la raigambre latina de conceptos como república (res publica), Senado (senatus), pueblo (populus), ley (lex), consenso (consensus), dictadu-

Ver, por ejemplo, El Legado de Roma, Una nueva valoración, de Richard Jenkyns (ed.), especialmente el capítulo XIV. El derecho, de Robert Feenstra, págs. 356-373. Ed. Crítica, Barcelona, 1995.

2 Manlio Bellomo, La Europa del Derecho Común, II Cigno Galileo Galilei, Roma, 1996 (Primera Edición española). También Bartolomé Clavero, Historia del Derecho: Derecho Común, Ed. Universidad de Salamanca, 1994. Bernardino Bravo Lira, Derecho Común y Derecho Propio en el Nuevo Mundo. Editorial Jurídica de Chile, Santiago. 1989.

4 Ahora último, Bernardino Bravo Lira y Sergio Concha (editores), en Codificación y Descodificación en Hispanoamérica, Tomol.

5 Especialmente, Bernardino Bravo Lira, La Universidad en la Historia de Chile. Ed. Pehuén, Santiago, 1992. Ahora, él mismo en "Estudios Jurídicos y Estado Modernizador. Cultura de Abogados en Chile 1758-1998", en Rev, Chilena del Derecho, vol. 25, $n^{\circledR} 3$, Santiago, 1998. 
ra (dictadura), plebiscito (plebiscitum), autoridad (auctoritas), poder (potestas) ${ }^{6}, \mathrm{y}$ tantos otros, no sólo manifiestan una evidente continuidad idiomática propia de las lenguas romances, sino que hoy forman parte cotidiana de nuestro pensamiento e instituciones políticas.

En el plano de los procesos históricos y políticos esto se repite con nitidez, y así lo han percibido los estudiosos de numerosos paises y universidades. En este ámbito no podemos dejar de mencionar, sólo a manera de ejemplo, los procesos de expansión territorial conocidos como imperialismo, la importancia de articular leyes y costumbres (mores) para el éxito de las fórmulas políticas, la ruptura de los consensos básicos que sustentan un régimen político como fase previa del derrumbe de un sistema, o bien el proceso de concentración del poder en manos de una persona, encarnado en Roma en la figura de Julio César. De ahi emanan conceptos tales como cesarismo presidencial o Kaiser por nombrar algunos de los más recurridos y familiares?

Por ello es que resulta interesante, junto con estas reflexiones, estudiar un problema específico de las instituciones políticas romanas, como es la constitución mixta. Esta es la fórmula política que, según el pensamiento ampliamente extendido en los sectores dirigentes de Roma, era la clave de su éxito, estabilidad y superioridad: en definitiva, la grandeza que le permitió a Roma ser un gran imperio. Esa visión, asumida como real (histórica) entre los romanos, fue registrada y trabajada intelectualmente por el historiador griego Polibio $^{8}$ a mediados del siglo II antes de Cristo y por Cicerón ${ }^{9}$ un siglo después.

Resulta interesante seguir - como lo hacemos concretamente en el presente trabajo - la visión política del orador de Arpinio, por varias razones. Por un lado, Cicerón no sólo fue el pensador político más importante de Roma, sino que desarrolló una actividad política que le llevó a alcanzar las más altas magistraturas romanas y, en particular, el consulado del año 63 , que él mismo recordará como su año de mayor gloria ${ }^{10}$.

Además, y esto es muy importante cuando nos referimos a historia clásica, de Cicerón tenemos la suerte de haber conservado una gran cantidad de obras, entre estudios filosóficos, políticos, cartas (de las que escribió numerosas y las que tenemos por

6 Ver George Duby, La civilización latina, Ed. Laia, Barcelona, 1989.

7 Podemos decir que el conocimiento de la historia romana nos permite también aproximarnos mejor a otros procesos análogos vividos por otros pueblos, vg, el imperialismo inglés, la cristinanización de América o los cesarismos militares contemporáneos.

8 Polibio, Historias, Libro VI. Una buena traducción chilena, con Introducción y notas es la de Genaro Godoy, Ed. U. de Chile, Ed. Andrés Bello, Santiago, 1970.

9 Cicerón, Sobre la República. Hay muchas ediciones, hemos utilizado preferentemente en esta ocasión la de Alvaro D’Ors, en Biblioteca Clásica Gredos, Madrid, 1984.

10 Sin pretender agotar el tema, pueden revisarse las siguientes biografías de Cicerón: David Stockton, Cicerone, Rusconi, Milán, 1984; Pierre Grimal, Cicerón, Fayard, Francia, 1986; Elizabeth Rawson, Cicero, A Portrait, Bristol Classical Press, 1994. La biografía fundamental, en cuanto fuente histórica, es la de Plutarco, en sus Vidas Paralelas, Vida de Cicerón. 
cientos), o ensayos en general ${ }^{11}$. Ello nos permite seguir su pensamiento con precisión $y$, a través de su vida política, podemos reconstruir la crisis de la república romana en el siglo I antes de Cristo ${ }^{12}$.

Cicerón nació el año 106 a.C., cuando comienzan a verse con claridad algunas manifestaciones de poder personal, cuando el poder senatorial es cuestionado y cuando se manifiesta la importancia de los ejércitos para los comandantes y su traducción en términos de poder político. Cicerón muere el 43 a.C., asesinado, después de la formación del triunvirato constituido por Marco Antonio, Octaviano (después Augusto) y Lépido ${ }^{13}$. Un año antes había sido asesinado Julio César ${ }^{14}$ y tal como murieron cientos de senadores y miles de romanos durante el cruento siglo de las guerras civiles.

Esa misma claridad de una crisis republicana, hoy diríamos integral, lleva a Cicerón a redactar entre los años 54 y 51 a.C. su obra Sobre la República (De Republica) ${ }^{15}$. , donde se refiere a la constitución romana, sus instituciones y formas de funcionamiento $y$ sus virtudes que hicieron grande a Roma.

El libro está escrito en forma de diálogo, dividido en seis libros (hoy serían capítulos). El diálogo ficticio, desarrollado el $129 \mathrm{aC}$, ochenta años antes de la fecha real del libro, tiene como sus actores principales a Publio Escipión (el Africano, destructor de (artago) y un grupo de amigos principales en Roma. A su vez, Cicerón intercala sus opiniones y posturas personales, sobretodo al comienzo de cada libro ${ }^{16}$.

No debemos entender la obra como un tratado filosófico sobre asuntos de gobierno, al modo platónico, sino más bien como el escrito de un político que reflexiona ${ }^{17}$.

La obra de Cicerón es vastisima. En español, las Obras Completas de Marco Tulio Cicerón, Vida y Discursos, de Ediciones Anaconda, Buenos Aires, 1946, comprende 6 volúmenes, que en total suman más de 4000 páginas

El llamado segundo triunvirato fue una magistratura "anómala" dentro de la crisis republicana, con inmenso poder y repercusión. Los tres viri rei publicae constituendae como se les llamó, decretaron las proscripciones que llevaron a la muerte de Cicerón. Cfr, especialmente, Plutarco, Vidas Paralelas (Marco Antonio); Suetonio, Vida de los Doce Césares (Augusto); Apiano, Guerras Civiles. Respecto de Cicerón en este período, Maria Bellincioni, Cicerone politico nell'ultimo anno di vita, Paideia, Brescia, 1974.

14 Plutarco, Vidas Paralelas (César); Suetonio, Vida de los Doce Césares (Julio César).

15 En el ámbito de las instituciones republicanas de Roma, este libro de Cicerón debe ser complementado con su De legibus, Sobre las Leyes, comenzado el 52 y retomado años después. Recomendamos la edición en español de Alvaro D'Ors, M. T. Cicerón. Las Leyes, Instituto de Estudios Políticos, Madrid, 1970.

La verdad es que si bien Cicerón utiliza el comienzo de cada libro para hablar personalmente sobre las instituciones romanas, lo cierto es que también se expresa a través de los personajes del diálogo, especialmente a través del principal de ellos, Escipión, llamado Africano

17 Esta idea es central, aunque muchos estudios ven también en el De Republica de Cicerón una obra de reflexión filosófica. Ver, por ejemplo. Malcolm Schofield, "Cicero's Definition of Res Publica", en J. G. F. Powell (ed). Cicero The Philasopher, Clarendon Press, Oxford, 1995. Con todo, en la obra ciceroniana y en especial en el De Republica aparece ampliamente destacada la superioridad de la vida política sobre la mera filosofía. Cfr, especialmente, en la Introducción al Libro I. cuando expone personalmente, sin la mediación de los interlocutores del diálogo. 
Esta idea es clave: Cicerón es un hombre que cree en la superioridad de la vida política sobre la filosófica ${ }^{18}$, aunque en los momentos en que está alejado de las lides electorales y de poder, decide pensar la república, con seguridad como una forma más de servirla. En este sentido, la república ciceroniana es un complemento histórico-pragmático, romano, de la tradición especulativa griega ${ }^{19}$.

La obra está escrita refiriéndose a la mejor constitución conocida, según los romanos, es decir, aquella que fundaron sus antepasados en una pequeña ciudad hace ya varios siglos. Esa república, superior, armónica, participativa, cuyos hombres eran modelos de virtud, en el siglo I ha entrado en crisis y Cicerón no está ajeno a esta percepción, por lo demás bastante extendida y clara en su época.

Pero él intenta una salida ${ }^{20}$, no ve la crisis (¿o no quiere verla?) como definitiva, piensa que todavía es posible volver a los tiempos mejores de la República, aquellos tiempos que llevaron a decir a Escipión el Africano que, "de todas la repúblicas, no hay ninguna que, por su constitución, por su estructura o por su régimen, sea comparable con aquélla que nuestros padres recibieron de los antepasados y nos transmitieron a nosotros" 21 .

\section{LA CONSTITUCION MIXTA EN ROMA}

"Digo, pues, solemnemente, así lo pienso y afirmo, que, de todas las repúblicas, no hay ninguna que, por su constitución, por su estructura o por su régimen, sea comparable con aquella que nuestros padres recibieron de los antepasados y nos transmitieron a nosotros." 22 Esta es la forma solemne que utiliza Escipión para responder a la pregunta que se le ha hecho sobre cuál cree él que es la mejor forma constitucional de ciudad, que le formulara Lelio al invitarlo a disertar sobre la república. El Africano, conocedor de la teoría política, pero sobretodo de la práctica en el gobierno de la ciudad, respondió que la mejor forma era, precisamente, esa constitución que había permitido la grandeza de Roma y su estabilidad.

18 La idea se repite en otras obras de Cicerón, especialmente en el De Officiis, Sobre los Deberes. En definitiva para él la virtud más excelsa es, sin duda, la del que se esfuerza por el ejercer el gobierno de la república, del hombre que vive para servir a los demás. Cicerón, Sobre la República, Ed. Gredos, Madrid, 1984. Ver. especialmente, la Introducción de Alvaro D’Ors, págs. 731.

Plantea diversas soluciones que no son temas de este trabajo. Valga decir, sin embargo, que se orientan a la recuperación de la armonía social perdida mediante las fórmulas del Consensus omnium bonorum (consenso de todos los buenos, los bienpensantes) y la concordia ordinum (es decir, la concordia entre el Senado y el orden ecuestre). Por otro lado, al ver que la hora del poder personal ha llegado en Roma, propone la idea de princeps, un rector o moderador de la República, pero que actúa dentro de los marcos tradicionales de la Roma republicana. Sin embargo se da una paradoja: Cicerón busca una solución por medio de la palabra en el Foro, mientras el fin de la república se resolvía por las armas en los campos de batalla.

21

Cicerón, Sobre la República, 1, 46,70.

22

Cic., De Rep., 145,69. 
Frente una pregunta diferente a la planteada por Cicerón, el historiador griego Polibio $^{23}$ había llegado a la misma conclusión en la segunda mitad del siglo II a.C.. En efecto, en el libro VI de sus Historias, el autor busca una explicación a la supremacía romana y su imponente expansión por el mediterráneo, que le había permitido pasar de ser una pequeña ciudad a ser un gran imperio. ${ }^{24}$ ¿Cuál es el secreto? Que en Roma no tiene vigencia ninguna de las fórmulas de gobierno tradicionales, como la monarquía, la aristocracia o la democracia, sino una forma superior que incluye las virtudes de todas ellas y que, en el caso romano, tiene su expresión en el poder de los cónsules, el Senado y las asambleas populares respectivamente.

"De este modo, al tener los tres órdenes el poder de ponerse trabas o de apoyarse mutuamente, su disposición da los mejores resultados en todas las circunstancias; por eso no es posible encontrar una forma de gobierno más perfecta que ésa. Cuando un peligro, amenazando a los romanos desde el exterior, les obliga a pensar y a actuar de completo acuerdo, entonces la fuerza de su constitución es tal que no se descuida ninguna de las medidas necesarias, porque todos se preocupan a porfía de hacer frente a la situación, y las decisiones tomadas son ejecutadas sin retraso, porque todos los esfuerzos colectivos o individuales, se combinan para conseguir el objetivo que se han propuesto. He ahí como Roma debe a su constitución el ser invencible y llevar a buen término todo lo que ha emprendido." 25

Polibio, historiador griego, ha vivido ya mucho tiempo en Roma, y ha visto funcionar por sus propios ojos las instituciones romanas, particularmente por su cercanía al círculo de Escipión Emiliano ${ }^{26}$, lo que le ha permitido observar desde muy buena posición la constitución romana. La tesis de Polibio contiene principalmente dos proposiciones: una general, y es que hay tres clases fundamentales de gobierno (monarquía, aristocracia y democracia), siendo el gobierno más perfecto el que concilia armónicamente a las tres, y una particular, que es el caso de la constitución romana. Después viene la demostración: la constitución romana no es una forma exclusiva de gobierno; se encuentran en ella los tres principios primordiales, monárquico, aristocrático y democrático; esos tres principios se combinan y se equilibran de la manera más satisfactoria. Finalmente, la conclusión: su sistema contitucional le significa a Roma las mejores condiciones de desarrollo y las más prósperas consecuencias.

La parte esencialmente teórica de la tesis no es novedosa. Por el contrario, el ideal de buen gobierno estaba presente en la literatura griega, especialmente en la Poli-

Polibio fue un historiador griego, nacido hacia el 200 aC, autor de las Historias.

24

Sobre la expansión romana es interesante revisar no sólo la literatura que la describe, sino especialmente los diferentes atlas históricos publicados, que dan cuenta de ese crecimiento. Al respecto es importante la obra de Michael Grant, Atlas of Classical History (From 1700BC to AD 565), o The Penguin Historical Atlas of Ancient Rome, de Chris Scarre, recientemente publicado. Este último tiene el valor, además, de incluir descripciones de los mapas.

Polibio, Historias, VI, 11, 18. EI subrayado es nuestro.

26

El Círculo de Escipión lo compone Cicerón y un grupo de amigos, especialmente Lelio y Furio Filo, filohelénicos y con intereses en filosofia y literatura. Tuvieron contactos cercanos con Terencio. Panecio y Lucilio. Oxford Classical Dictionary, Scipionic Circle, P. 963-964. 
tica de Aristóteles. ${ }^{27}$ Lo que es más interesante es la segunda parte de la argumentación, la aplicación de los principios a la constitución romana. La idea - asumida como realidad propia en los círculos gobernantes romanos - de que su forma de gobierno era integradora de los diversos sectores sociales, toma con Polibio una expresión escrita que será ampliamente aceptada. Esta tesis, en plena crisis republicana, será desarrollada por Cicerón en dos de sus obras: De Republica y De Legibus.

En efecto, en el De Republica, Cicerón plantea la discusión ficticia de un diálogo en que el tema principal es, precisamente, la república y las formas de gobierno.

Insatisfecho por los escritos dejados por los autores griegos, Escipión - el principal interlocutor de diálogo - cree absolutamente necesario complementar cualquier argumento con la práctica romana del gobierno, aprovechando la experiencia que el mismo tenía en los asuntos de la república. ${ }^{28}$ Esta explicación es reflejo de la nueva forma propuesta para el estudio del tema, que a los elementos filosóficos y teóricos añade los históricos o pragmáticos.

El Africano comienza su discurso propiamente político definiendo la res publica, la cosa pública, como aquello que pertenece al pueblo, es decir, ese conjunto de una multitud asociada por un mismo derecho que sirve a todos por igual ${ }^{29}$. La causa de esa asociación no estaría dada por la indigencia humana, sino por cierta tendencia asociativa natural de los hombres. Para poder perdurar, toda república debe, necesariamente, regirse por un gobierno, el cual debe servir siempre y ante todo a aquella causa, con un derecho que sirve a todos los hombres por igual.

\section{¿Qué formas pueden adoptar estos gobiernos en su ejercicio?}

Al respecto, parece evidente que el gobierno puede atribuirse a una persona, a unas pocas escogidas o a la muchedumbre de todos. De esta manera, cuando el gobierno lo ejerce uno llamamos a ese gobernante rey y a esa república la denominamos monarquía. Cuando la ciudad está al mando de unos pocos, estamos frente a una forma de república aristocrática regida por los nobles. Finalmente, si todo lo puede el pueblo, estamos en una ciudad popular. "Cualquiera de estas tres formas - afirma Escipión - si sirve para mantener aquel vínculo que empezó a unir en sociedad pública a los hombres, no es perfecta ciertamente, ni ninguna de ellas es la mejor, pero sí es tolerable, y cada una puede tener ventajas sobre las otras"..$^{30}$

Tanto un rey justo y sabio como un grupo de nobles ciudadanos, e incluso el mismo pueblo, pueden ofrecer estabilidad a la república. Pese a ello, la monarquía, la aristocracia y la democracia, presentan limitaciones propias de las formas puras de gobierno y de cada una en particular, que lleva a que si bien son tolerables, no resultan óptimas.

\footnotetext{
27

Aristóteles, Politica, II, 3, 10-11.

28

Cic., De Rep, 122,35-36.

29 Cic., De Rep., $125,39$.

30 Cic.. De Rep., 126,41. Cicerón distingue entre las formas tolerables, que son aquellas que sirven al bien común de la ciudad y no al bien particular del gobernante, de aquella que podemos considerar perfecta.
} 
Un primer gran defecto es que la exclusividad de cada una de ellas impide aprovechar las virtudes de las otras formas tolerables. Así, por ejemplo, en los reinos los demás ciudadanos quedan demasiado apartados de todas las actividades de gobierno. En el sistema de los mejores, por su parte, la muchedumbre no disfruta de libertad por cuanto no tiene poderes para el gobierno de la comunidad. Cuando todo lo puede el pueblo, por último, la igualdad se vuelve injusta pues no respeta grados de dignidad.

Sin embargo, las formas simples de gobierno, que no tienen mezclas ni combinaciones presentan un segundo defecto, más perjudicial aún: todas ellas tienden a una mala forma próxima por una pendiente resbaladiza. ${ }^{31}$ La idea de mutación o degeneración en las formas de gobierno no es original de Cicerón. Aunque con diferencias, ya Polibio la había planteado en el libro VI de sus Historias un siglo antes. ${ }^{32}$

Para el historiador griego, hay al menos dos causas en el cambio constante e ininterrumpido de los gobiernos. La primera tiene su origen en la anaciclosis, es decir, el ciclo recurrente de las seis formas de gobierno en virtud del cual la monarquía (el gobierno original) se transforma en tiranía, la aristocracia en oligarquía y la democracia en oclocracia: "este es el ciclo de las formas de gobierno, este el orden natural, según el cual ellas se mutan y transforman y de nuevo vuelven al mismo punto." 33

La segunda explicación es de carácter "biológico", por la cual se compara a la república con un organismo vivo, que tiene un proceso natural de nacimiento, crecimiento, apogeo, decadencia y muerte. ${ }^{34}$

Cicerón a su vez, también observa los cambios en las formas de gobierno, aunque sin la rigidez del planteamiento de Polibio. Eso es natural, por cuanto la postura ciceroniana no tiene su origen sólo en la teoría política, sino sobretodo en la práctica histórica romana. "De la forma de gobierno de reyes sí que es natural y muy cierto el siguiente cambio: cuando el rey empieza a ser injusto, pronto perece aquella forma, y el rey se convierte en tirano, forma pésima próxima a la mejor; entonces, si los nobles suprimen al rey, lo que ordinariamente ocurre, la república pasa a la segunda de las tres formas de gobierno: la que más se acerca al gobierno de reyes, o sea, el gobierno paternal de unos jefes que dirigen bien a su pueblo. Si es el pueblo, en cambio, el que por sí mismo mata o expulsa a un tirano, entonces el pueblo se comporta con mayor moderación mientras se da cuenta y valora su hazaña, y se alegra de ella, deseando conservar la república por él constituida; pero cuando el pueblo mata a un rey justo o le despoja de su reino, o también, como ocurre más frecuentemente, le toma gusto a la sangre de los nobles y somete la república entera a su propio capricho, entonces, pienso que no hay mar ni fuego que sea más difícil de aplacar que la muchedumbre desenfrenada por su insolencia." 35 Y, siguiendo a Platón, explica en qué termina el poder excesivo del

Con esto Cicerón sigue la doctrina aristotélica, también utilizada por Polibio, que distingue las formas pueras de las degeneradas.

32 Polibio, Historias, libro V1. También es conveniente revisar el capítulo V del Libro Polybius, de Walbank, págs. 130-156.

33

Polibio, Historias, VI, 9,10

34 Polibio, Historias, VI, 9:13-14;57.

35 Cic., De Rep., 142,65. 
pueblo. "Porque, del mismo modo que del poder excesivo de los gobernantes nace su ruina, así también la misma libertad somete a servidumbre a tal pueblo excesivamente libre. Así todos los excesos, cuando resultan más propicios, se mudan en sus contrarios, $y$ esto sucede sobre todo en las repúblicas, de suerte que aquella excesiva libertad, lo mismo para los pueblos que para los particulares, se muda en excesiva servidumbre. Por lo tanto, de esta excesiva libertad se engendra el tirano y una servidumbre muy injusta y dura." 36

Como conclusión, Cicerón estima que de esta manera "vienen como a quitarse la pelota de la república, los tiranos a los reyes, y a aquellos los jefes o los pueblos, y a éstos las facciones o los tiranos, y nunca dura mucho el mismo tipo de república." ${ }^{37}$

En este contexto, es evidente que aparece como la mejor forma de gobierno aquella combinada y moderada que se compone de los tres primeros tipos de república, la monarquía, la aristocracia y la democracia. Porque conviene a la república que haya algo superior y regio, otra parte atribuida a la autoridad de los jefes o mejores $y$, finalmente, que algunas cosas queden reservadas al arbitrio y voluntad de la muchedumbre. "Esta constitución tiene, en primer lugar, cierta igualdad de la que no pueden carecer lo hombres libres por mucho tiempo; luego estabilidad, puesto que de una forma pura fácilmente degenera en el defecto opuesto..... lo que no sucede en esta otra constitución mixta y moderada de república, si no es por graves defectos de los gobernantes..." 38

De este modo, Cicerón culmina el primer libro de su República con aquella afirmación antes mencionada: que de todas las repúblicas no hay ninguna que tenga la perfección que la transmitida de generación en generación por los romanos. Así, promete Escipión en el diálogo que procurará demostrar cómo es la república romana y por qué es la mejor. ${ }^{39}$

\section{LOS CONSULES, EL SENADO Y LOS PODERES DEL PUEBLO}

En la constitución romana, las diferentes formas de gobierno tienen su expresión formal en diferentes instituciones. ${ }^{40} \mathrm{El}$ poder monárquico está representado en los dos cónsules; el Senado constituye la manifestación de la forma aristocrática, mientras el poder democrático cobra vida en las asambleas populares. La explicación del funcionamiento de estas instituciones así como la distribución de poderes entre ellos es explica-

Cic., De Rep., 144,68

37

Cic., De Rep., 144,68.

38

Cic., De Rep, 145,69

39

Cic., De Rep., 146,70. La comprobación que Escipión ha prometido hacer forma parte de lo que será el Libro II de la obra de Cicerón.

40

Sobre las instituciones políticas en Roma y la distribución de poderes hay importantes obras. Entre otras, Las Instituciones politicas romanas de Leon Homo son de especial interés. Recientemente, J.M. Roldán. Instituciones políticas de la República Romana, AKAL, Historia del Mundo Antiguo, vol. 45. 
da por Cicerón en el De Republica y muy especialmente en el De Legibus, si bien las alusiones a estos temas cruzan toda su obra. ${ }^{41}$

\section{A. EL PRINCIPIO MONARQUICO Y LOS CONSULES}

La primera forma de gobierno adoptada en Roma fue la monarquía, el gobierno de los reyes, como ocurre en general en todas las sociedades políticas, entregándose el poder a las personas más justas y prudentes. ${ }^{42}$ Esta es la época en que fue fundada la ciudad y se eligió el lugar definitivo donde se establecería y se sentaron algunas de las bases de funcionamiento de la futura república. ${ }^{43}$ Los distintos reyes fueron sucesivamente integrando diversas instituciones al sistema político.

Sin embargo, muy pronto la monarquía propiamente tal cayó en desgracia para los romanos, especialmente por el recuerdo amargo que significaba el rey Tarquinio el Soberbio, último rey de Roma, que hace odioso el nombre de rey para todo el pueblo. ${ }^{44}$ Cicerón comprueba, por otra parte, que si uno solo ostenta mayor poder que los demás. y en forma permanente, - aunque exista un Senado y el pueblo tenga poder - esa república no puede dejar de ser ni de llamarse reino. ${ }^{45}$

Sin embargo, la ausencia de rey no excluye la vigencia que va a tener en la constitución romana el principio monárquico: quien llenará ese espacio será la nueva magistratura del consulado ${ }^{46}$, que representara la fortaleza de un gobierno central, pero sin los defectos que se le atribuían a los reyes. Sucesores directos de los reyes, los cónsules conservaron muchas de sus atribuciones e incluso de sus insignias y honores. La formación de esta magistratura es todavía oscura ${ }^{47}$, aunque hacia el año 500 ya funcionaba regularmente. ${ }^{48}$

41 Es especialmente ilustrativo revisar las cartas políticas de Cicerón así como algunos de sus discursos.

42 Cic., De Leg., III2,4. Cicerón llama la atención sobre lo mucha que duró en Roma el gobierno de los reyes.

43 Cicerón dedica una buena parte del libro II de su República a explicar el funcionamiento de los primeros monarcas. Cfr. De Rep., II 1-27.

44 Cic., De Rep., 137,58 y 40,62; 1127,49 y 30,52. "Así pues, con estos doscientos cuarenta años de gobierno de reyes o poco más, con los interregnos, y tras la expulsión de Tarquinio, el pueblo romano conservó un odio al nombre de rey tan grande como el deseo que había tenido de él después de la muerte, o mejor dicho, el tránsito de Rómulo; así como en aquella ocasión no podía carecer de rey, después de la expulsión de Tarquinio, no podía oíer hablar de reyes." (Cic., De Rep., $1130,52$.

45 Cic., De Rep., $11223,43$.

46 El consulado pasó a ser con el tiempo la más alta magistratura romana. Los cónsules - como magistrados epónimos dan nombre al año en el que cumplen su función. Heredan el antiguo imperium real, limitado por la anualidad y la colegialidad.

47 Cfr. Homo, Leon. Instituciones politicas romanas, págs. 24-26; Instituciones Políticas de la República Romana, AKAL, Historia del Mundo Antiguo, vol. 45, . págs. 28-30.

48 Cic., De Rep., I131,54. En esta parte del diálogo Cicerón se refiere a la ley consular de Lucio Valerio Potito y Marco Horacio Barbado, cónsules el año 499 aC. 
La nueva magistratura estuvo representada por dos cónsules - originalmente llamados pretores - que ejercerían su poder por un año, "potestad que por sí misma y de derecho era como la de los reyes." 49

Son dos, sin embargo, las diferencias radicales que presenta el consulado respecto al poder antes ejercido por los reyes, que significan una doble limitación para los cósules: la colegialidad y la anualidad, garantía de que en el futuro nadie ejercería el poder absoluto en un pueblo libre. Así resume Cicerón la posición constitucional del consulado: "Haya dos magistrados con poder regio, y que se titulen pretores, porque marchan delante, jueces, porque juzgan, y cónsules, porque consultan. Tengan la autoridad máxima en el ejército, y no estén subordinados a nadie. Tengan como ley suprema la salvación del pueblo." ${ }^{50}$

En lo sucesivo, el poder ejecutivo queda en manos de estos dos magistrados, que en virtud del principio de la par potestas tienen un derecho de intercesión mutua. En síntesis: rey no; poder regio, sí. "Pero como la forma política del reino, aceptada al principio, fue repudiada, no tanto por los defectos del reino cuanto del rey, diremos que tan sólo se repudió el nombre de rey, y que la institución subsiste siempre que un magistrado tenga poder sobre todos los otros.... En efecto, el cónsul tiene una autoridad tal, concedida por el derecho, que deben obedecerle todos los otros magistrados, excepto el tribuno, que fue creado después a fin de evitar una repetición del pasado. Esto disminuyó la autoridad consular, en primer lugar, porque surgió quien no estaba supeditado a ella, y, en segundo lugar, porque aportó un medio de protección, no sólo para los otros magistrados, sino incluso para los particulares desobedientes al cónsul." 51

\section{B. EL PRINCIPIO ARISTOCRATICO Y EL SENADO}

No cabe duda que el Senado fue para Cicerón el órgano fundamental de la República Romana. Tan claro es esto que le asigna la mayor importancia en sus diferentes obras y, por otra parte, ve en la crisis del Senado la muestra más elocuente de la crisis de la República en su totalidad.

En el Senado está representado el principio aristocrático de gobierno, central en el esquema de constitución mixta defendido por Escipión en el De Republica. El origen de esta institución aparece cuando Rómulo contó en su gobierno con el apoyo de ciertas personas principales llamados "padres", cuya autoridad y consejo sirvió como especie de senado. Con esto, reafirmó lo que Licurgo ${ }^{52}$ había hecho en Esparta, y comprobó que las ciudades se gobiernan y rigen mejor por el mando de uno solo y el poder real, si se agrega a ese poder la autoridad de los mejores. ${ }^{53}$

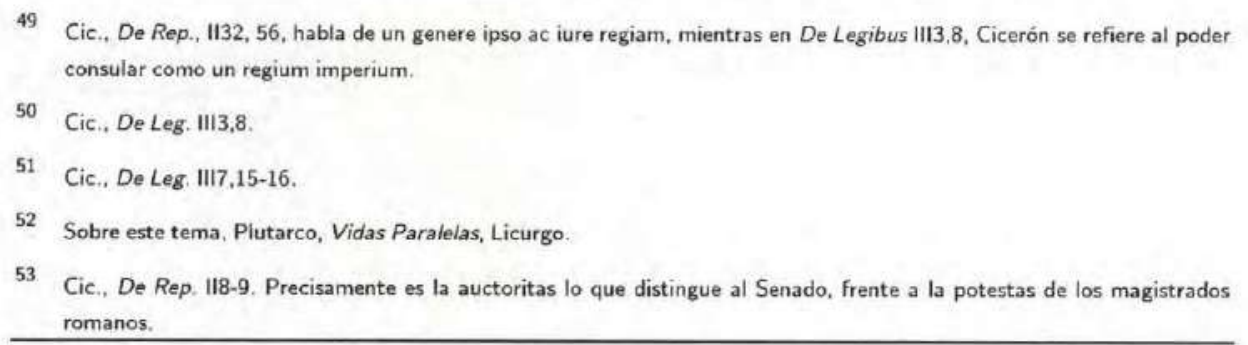


Escipión llega a decir por esto que fue precisamente Rómulo quien creó estos "dos egregios puntales de la República, los auspicios y el senado." ${ }^{54} \mathrm{La}$ institución había sido tomada también de los griegos, que tenían la gerusía, alto consejo que asesoraba al rey. Los romanos imitaron esto y lo tradujeron, llamándolo senado (los Ilamados padres), aunque quedaba encima la potestad efectiva y el nombre de rey. ${ }^{55}$

Acabado el tiempo de los reyes, la autoridad del Senado siguió existiendo, y Escipión le atribuye los mayores logros. "En esa época (siglo $\mathrm{V} \mathrm{aC}$ ), el Senado mantuvo la república de manera que, siendo libre el pueblo, unas pocas cosas las hiciera el pueblo y la mayoría se rigieran por la autoridad, la decisión y tradición del senado, y que unos cónsules tuvieran, sólo por un año, una potestad que por sí misma y de derecho era como la de los reyes, y se observaba decididamente, lo que era muy importante para asegurar el poder de los nobles, que los acuerdos de los comicios populares no valieran si no los autorizaba la autoridad de los padres del Senado." ${ }^{56}$

El mérito de esta institución no estaba dado tanto por los poderes que ejercía como por su virtud. Pese a los intentos hechos en algún momento para disminuir su influencia, su "autoridad seguía siendo importante y grande, y florecía sobretodo por la prudencia y energía de los que defendían a la ciudad con las armas y con su consejo, pues sobresalían entre todos los demás por su dignidad, pero eran a la vez más austeros, sin ser tampoco más ricos, de manera que se apreciaba más en la vida pública su virtud personal por el hecho de que se apreciaba más en la vida pública su virtud personal por el hecho de que se preocupaban diligentemente de los asuntos privados de cada uno de los ciudadanos, con ayuda de su consejo y acción." 57

Con todo, es evidente que el Senado conservó dentro de la república romana su posición preeminente, se bien sus poderes y funciones coexistieron con las ejercidas por los cónsules y las asambleas populares. le atribuia?

¿Qué hacía el Senado? ¿Cuáles eran sus poderes más allá de la auctoritas que se

Las funciones del senado Cicerón las expone con mayor detalle en el De Legibus.

Hablando el propio Cicerón, señala que el Senado tiene que componerse "con los que ocuparon la magistratura, pues es cosa grata al pueblo el que nadie suba a los cargos más altos sino por elección popular, quedando impedida la libre designación por el censor." 58

Cic., De Rep. I110,17. Sobre los auspicios es interesante lo manifestado por Ortega y Gasset en su ensayo "Del Imperio Romano".

55 Cic., De Rep. 1128,50

56 Cic., De Rep. II 32,56. En esta afirmación queda de manifiesto una idea que se repetirá frecuentemente en el pensamiento ciceroniano y en la realidad política romana: que el sistema mixto de gobierno no implica equivalencia de poderes y funciones, sino que sólo una participación de todos dentro del sistema. En la práctica, evidentemente, el Senado tenía más poderes que aquellos que ejercia el pueblo

57 Cic., De Rep. 1134,59 . 
La ley agrega "que sus decretos sean válidos" y "que este orden senatorio sea sin tacha y sirva de ejemplo a los demás" ${ }^{59}$ Este último aspecto es relevante, por cuanto Cicerón ya había expresado como una de las principales funciones del gobernante el de servir de espejo (speculum) a los demás ciudadanos. En el caso del Senado esta función se confirma y se multiplica, por cuanto así como las ciudades se corrompen por los vicios de los nobles, asimismo se enmiendan y corrigen con su buen comportamiento. "Las faltas de los nobles, con ser un gran mal en sí mismas, no lo son tanto cuanto porque son muchos los que imitan a los nobles. Pues se puede ver, si quieres recorrer la historia, que, tales fueron los nobles de la ciudad, tal fue la ciudad; y que a cada cambio de costumbres surgido en los nobles, seguía otro igual en el pueblo." 60

La institución del senado se mantuvo prácticamente inalterada durante la república, con 300 miembros. La inclusión en el Senado se produce por elección popular y por el nombramiento de los censores (el pueblo elegía indirectamente, pues los censores debían tener en cuenta a todos los ex magistrados al completar el album de los trescientos en cada lectio Senatus). Durante el siglo I se transforma esta institución, en cuya crisis ve Cicerón gran parte de la crisis de la república. Así, Sila dobló los efectivos del Senado, y en tiempos de Julio César esta cifra aumentó a novecientos. Finalmente, Augusto rebajó nuevamente la cifra a seiscientos, número que se mantuvo durante el Imperio.

\section{LOS PODERES DEL PUEBLO}

Dentro del esquema de la constitución mixta, es natural que también el pueblo ${ }^{61}$ tenga sus derechos y prerrogativas. Así lo ha expresado claramente Cicerón en el De Republica y en el De Legibus.

La participación del pueblo se entiende en un sistema de libertad en que la primacía permanece en el Senado: éste mantiene "la república de manera que, siendo libre el pueblo, unas pocas cosas las hiciera el pueblo y la mayoría se rigieran por la autoridad, la decisión y la tradición del senado." 62 Con esta fórmula se salvaba el equilibrio constitucional descrito por Cicerón, en que al pueblo le correspondía tener suficientes grados de libertad. ${ }^{63}$

sino que también entre las personas que sobresalieran por sus cualidades o su posición social.

60

61

Aquí pueblo no está entendido como base del orden político, que define a la res publica como una res populi. (Cic., De Rep. 125,39.) Cuando hablamos de poderes del pueblo dentro de la constitución mixta si nos referimos al principio democrático, donde se entiende gobierno del pueblo como aquel gobierno "ejercido por el pueblo".

62

63

Asi como los magistrados debian tener suficiente potestad y el consejo de los hombres principales suficiente autoridad. Cfr. Cic., De Rep. II33,58. 
En diversos párrafos del De Legibus Cicerón se refiere más concretamente a los poderes del pueblo. En cuanto a los tribunos ${ }^{64}$, señala que "los diez que la plebe nombre para propia defensa contra la violencia sean sus tribunos, y que lo que ellos prohiban o propongan a la plebe sea válido; sean inviolables; y que no se deje a la plebe huérfana de tribunos." 65

El tribuno era sacrosanctus (inviolable, lo que le daba derecho a protección). Su función principal era proteger a los plebeyos, que de hecho operaba por la intercessio o veto, la prohibición impartida por el tribuno a la acción de un magistrado. Desarrolló la tribunicia potestas, para velar por la república, entendiendo en procesos de alta traición (perduellio) o en los que atentaban a la dignidad del pueblo romano (maiestas). Finalmente, como magistrados de la plebe podían presidir las asambleas plebeyas, los concilia plebis, donde por medio de los plebiscitos se desarrollaba la tarea legislativa de la república y, en ciertos casos, podía convocar al senado.

En De Legibus Cicerón explica que el surgimiento de los tribunos disminuyó la autoridad consular, por cuanto los tribunos no estaban supeditados a ella y, además, porque aportó un sistema de protección para los otros magistrados y para los particulares desobedientes al cónsul. Quinto considera el surgimiento de los tribunos como una gran desgracia, porque con ello "decayó el prestigio de los nobles y se reforzó la potencia de la masa." 66 Después felicita las leyes de Sila contra el tribunado.

Cicerón aprovecha esa oportunidad para defender la institución, más allá de que haya habido tribunos perniciosos. La violencia del pueblo, estima Cicerón, sería mucho más cruel y desmesurada si no tuviera este jefe, con quien es más tratable. Respecto de su propia vida, sostiene que no se enfrentó él contra el tribunado como tal, sino solamente con ciertas gentuzas. ${ }^{67}$

En cuanto a las asamblea populares, sus sesiones han de ser con modales. Debe apartarse de ella toda violencia, prevaleciendo el veto de la potestad igual o mayor. Si surge alguna turbación en la asamblea, sea culpa del presidente, y sea ciudadano benemérito el que interponga veto a una propuesta perniciosa. Tampoco puede decidirse pena capital si no es en la asamblea de las centurias y por las sque los censores inscribieron en aquellas clases del pueblo. ${ }^{68}$

De este modo, los poderes de los comicios centuriados son de tres órdenes: elección de los magistrados superiores (cónsules, pretores y censores); voto de las leyes (tras la lex Hortensia serán los concilia plebis los que quedarán como órgano normal de la legislación a través de los plebiscitos), y el poder judicial de naturaleza controvertida. Esto incluye el funcionamiento como tribunal de apelación cuando un proceso juzgado

64 Fueron "creados sediciosamente dos tribunos de la plebe" (Cic., De Rep. I134,59.) Los tribunos después fueron elevados a diez y fueron integrados como magistrados de la república. 
por un magistrado da lugar a la provocatio ad populum (en especial en las causas que entrañan pena de muerte.)

\section{TEORIA Y REALIDADES EN LA CONSTITUCION MIXTA ROMANA.}

Cuando Polibio escribió las Historias en el siglo II a.C. o Cicerón el De Republica a mediados del siglo I a.C., ambos estaban pensando en una realidad histórica y política que tenía amplia aceptación en los círculos gobernantes romanos: que la constitución mixta era una realidad y que sus consecuencias eran felices para la república romana.

Como se ha visto, hay argumentos como para pensar que así fue en realidad, dada la distribución de poderes y deberes entre los cónsules, el senado y las asambleas populares. Polibio, en este sentido, fue bastante lejos, al señalar que "el poder estaba tan bien dividido y distribuido, que ni siquiera los romanos habrían podido decir con seguridad si su gobierno era en su conjunto aristocrático, democrático o monárquico. $Y$ no hay por qué asombrarse, ya que considerando el poder de los cónsules, se habría dicho que el estado romano era de forma monárquica, mirando el del Senado se habría dicho que era aristocrático; si alguien finalmente hubiese considerado la autoridad del pueblo, sin más demora habría definido como democrático el estado romano" ${ }^{69}$

Sin embargo, podemos perfectamente realizar algunas observaciones a la aparentemente inapelable descripción de la constitución mixta.

En cuanto a la mixtura social, no cabe duda que tanto Polibio como Cicerón describen una constitución que se ha actuado históricamente en Roma, pero también es evidente que la república romana no está matemáticamente dividida en la distribución de poderes y funciones. Por una parte, hay un claro predominio aristocrático, representado en los poderes ejercidos por los cónsules y el senado. Así, por ejemplo. resulta muy ilustrativa la descripción de Salustio en La Guerra de Yugurta: "La nobleza se transmitía el consulado de mano en mano. Cualquier hombre nuevo, por ilustrado que fuera, por buenas acciones que hubiera realizado, paracía indigno de ese honor y como contagiado por la mancha de su nacimiento." ${ }^{70}$ Es decir, si bien desde el punto de vista político el consulado era la expresión del poder monárquico, socialmente representaba el poder de la aristocracia en Roma. Respecto del Senado, no cabe duda que decide con más fuerza que las asambleas populares, y Cicerón, en este sentido, no esconde su apoyo a la primacía social y política de los nobles sobre el pueblo.

Al referirse a los puntos fundamentales de la república, Cicerón menciona a los auspicios y al Senado ${ }^{71}$ Después defiende permanentemente la auctoritas del Senado, destacando que se aseguraba en la constitución, "lo que era muy importante para asegurar el poder de los nobles, que los acuerdos de los comicios populares no valieran si no los aprobaba la autoridad de los padres del Senado." 72 Por otra parte, ya no sólo en el De Republica, sino que a través de sus diferentes obras y durante su vasta actua-

\footnotetext{
69 Polibio, Historias VI11. Similar idea, aunque sin igual tono categórico, sostiene Cicerón en el libro II del De Republica.

70 Salustio, Bell.Jug.63,7. Precisamente Cicerón fue el primer homo novus en acceder al consulado, el año 63.

71 Cic., De Rep. I110,17.

72 Cic., De Rep. 1132,56
} 
ción pública, Cicerón sostiene permanentemente posiciones que privilegian a los grupos más altos de la sociedad. Así, por ejemplo, se refleja en su propuesta política para superar la crisis republicana, cuando hace un llamado a la concordia ordinum, es decir, a la unión entre los grupos más representativos del orden ecuestre y el senado (ampliado más adelante con la proposición de un consensus omnium bonorum, que integra a "todos los buenos", independiente de su origen social.)

Por lo demás, hay muchas muestras de desprecio en el De Republica hacia las formas de gobierno popular o democrático. En boca de Lelio, se afirma que "ninguna otra forma de gobierno negaría mejor que constituye una república que esa que está absolutamente bajo la potestad de la masa" ${ }^{73}$ Y Escipión, en otra parte, sostiene que "de las tres formas de gobierno ( puras ), es esta ( la popular ) la menos digna de aprobación."

Desde el punto de vista constitucional resultan también claras las prevenciones del sistema en cuanto a que no prevalezca la mayoría. Los comicios centuriados estaban dispuestos de tal manera que la mayoría no tomara las decisiones. Así, además de las dieciocho centurias de los caballeros, el resto del pueblo fue dividido en cinco clases, distribuidas "de manera que los votos no estuvieran en poder de la muchedumbre sino de los más ricos", cuidando "lo que siempre debe cuidarse en una república, que no prevaleciera la mayoría" ${ }^{74}$

El sistema concebido por los romanos era el siguiente: las centurias de los caballeros más los de la primera clase suman ochenta y nueve, de un total de 193 centurias. De esto modo, con sólo sumar ocho centurias alcanzan el poder del pueblo, con lo cual se logran dos cosas: por una parte, que la multitud no quede excluida de voto, pues sería despótico, ni pueda prevalecer, pues sería arriesgado. "De este modo, no se impedía a nadie ejercitara el derecho al sufragio, pero tenía más valor aquel que más interés tenía en que la ciudad se hallara en el mejor estado". ${ }^{75}$

También podemos hacer una segunda observación sobre la constitución ideal descrita por Cicerón, esta vez respecto de la oportunidad de su exposición. No cabe duda que, más allá de las correspondientes puntualizaciones, Roma había logrado definir un sistema político integrador que, entre otras cosas, les había permitido superar con éxito las dificultades internas, vencer a los enemigos externos y mantener un sistema de convivencia perdurable en el tiempo.

Sin embargo, al momento que Cicerón escribe su obra, la constitución por él descrita ha entrado en un proceso de crisis, en que el consenso constitucional entra en decadencia y se apresta a ser reemplazado por un nuevo régimen político. No por nada Cicerón ubica históricamente su diálogo en el año 129 a.C., en el siglo donde Roma alcanza el equilibrio interno y externo que admirara Polibio. Pero el mismo autor griego, poco antes de finalizar el libro VI en que describe la constitución romana y sus vir-

73 Cic, De Rep. III33,45. Lelio agrega frases del siguiente tenor: "no veo cómo puede darse el nombre de república al dominio de la masa"; "esta unión de la masa es tan tiránica como la tiranía de una sola persona"; "no hay bestia más abominable que esa que tiene el nombre de popular".

74 Cic., De Rep.1122,39. 
tudes, alcanza a preanunciar el inicio de la decadencia romana. "Cuando un Estado sostiene Polibio -, después de liberarse de muchos y graves peligros, alcanza un poderío grande y sin contraste, es evidente que, como consecuencia del bienestar general los ciudadanos comienzan a llevar una vida dispendiosa y se hacen más ávidos de lo que sería oportuno del poder y la supremacía. Al seguir ellos por este camino, la avidez de dominio y el temor de quedar ignorados marcarán el comienzo de la declinación; acompañan a estos hechos, como causas de decadencia, el excesivo lujo y la molicie de las costumbres," 76 La rebelión partiría del pueblo, renuente a seguir obedeciendo a sus jefes. Asi, el pueblo se propondrá obtener la completa supremacia, a raíz de lo cual el gobierno obtendrá el nombre de libre democracia, pero será en realidad la peor de sus formas: la oclocracia. ${ }^{77}$

No es casual, por su parte, que Cicerón refiera su diálogo al 129 a.C., y evite referirse a la contingencia política. Sin embargo, en diferentes pasajes del De Republica es explícito en declarar que la contitución que Escipión alaba y que era orgullo de los romanos, dejó hace bastante tiempo su mejor forma. "Como sabéis, la muerte de Tiberio Graco, y ya antes de su muerte la conducta de su tribunado, dejó dividido un pueblo único en dos partes." ${ }^{78} \quad$ Esa visión pesimista se amplia en el libro $\mathrm{V}$, al recordar la famosa frase de Ennio que sostiene que "la república se funda en la moralidad tradicional de sus hombres" 79 Pero "¿qué queda de aquellas antiguas costumbres en las que decía Ennio que se fundaba la república romana? Las vemos ya caidas en desuso por el olvido, y, no sólo no se practican, sino que ni se conocen ya. Y iqué decir de los hombres? Porque las mismas costumbres perecieron por la falta de hombres, un mal del que no sólo debemos rendir cuentas, sino incluso defendernos como reos de pena capital. No por infortunio, sino por nuestras culpas, seguimos hablando de república, cuando hace ya mucho tiempo que la hemos perdido." 80

En tiempos de Cicerón, durante el siglo I aC, más allá de una valiosa historia institucional y militar, la república tradicional romana ya es parte de la historia y las instituciones y virtudes que la hicieron grande han sufrido modificaciones y decadencias. En este contexto se explica la búsqueda ciceroniana de la figura de un princeps, que a la cabeza del Senado y de la república, gobernara Roma. "En efecto, sostenía Cicerón en el Libro V de su obra sobre la República, como compete la ruta segura al timonel, la salud al médico y la victoria al general, así la vida feliz de los ciudadanos a este mode-

76 Polibio, Historias VI, 57. Similares causas de decadencia exponen Salustio en La Conjuración de Catilina y Cicerón en el De Republica.

77 La predicción de Polibio es de gran fuerza. Ha servido ella para afirmar que se refiere a los acontecimientos del año 133 , bajo el tribunado de Tiberio Graco, lo que no necesariamente es así, pues antes y después la república romana mostró indudables signos de descomposición. Cic., De Rep. 119,31 .

79

Con esta frase se inicia la tercera jornada del coloquio y el libro V del De Republica. El verso de Ennio - Moribus antiquis res stat romana virisque- es de los preferidos de Cicerón, "porque ni los hombres sin tales costumbres ciudadanas, ni las costumbres el gobierno de tales hombres, hubieran podido fundar ni mantener por tan largo tiempo una república tan grande y que difunde tan extensamente su imperio" Cic., De Rep. V1,1. 
rador de la república, para que esté segura de recursos, abundo en bienes, tenga gloria y viva honestamente; quisiera que él fuera el artífice de este principal y noble servicio entre los hombres" ${ }^{81}$ Sin embargo, ya era demasiado tarde. Como el propio Cicerón había sostenido en otra ocasión, en una carta a su hermano Quinto, rem publicam funditus amisimus: la república está completamente destruida. ${ }^{82}$

81 Cic., De Rep. V6,8. El moderator o moderador de la República es llamado de diferentes maneras. Así, en ocasiones aparece como el tutor et procurator rei publicae, y también como rector et gubernator civitatum, según lo expresa en el libro 1129,51 .

82 Cic., Ad Q. fr., 1,2,15. 